\title{
Kinetics of the $\mathrm{OH}+\mathrm{NO}_{2}$ reaction: Rate coefficients (217-333 K, 16- 1200 mbar) and fall-off parameters for $\mathrm{N}_{2}$ and $\mathrm{O}_{2}$ bath-gases
}

Damien Amedro ${ }^{1}$, Arne J. C. Bunkan ${ }^{1}$, Matias Berasategui ${ }^{1}$ and John N. Crowley ${ }^{1}$

$5 \quad{ }^{1}$ Division of Atmospheric Chemistry, Max-Planck-Institut für Chemie, 55128 Mainz, Germany

Correspondence to: John N. Crowley (john.crowley@mpic.de)

Supplementary Information

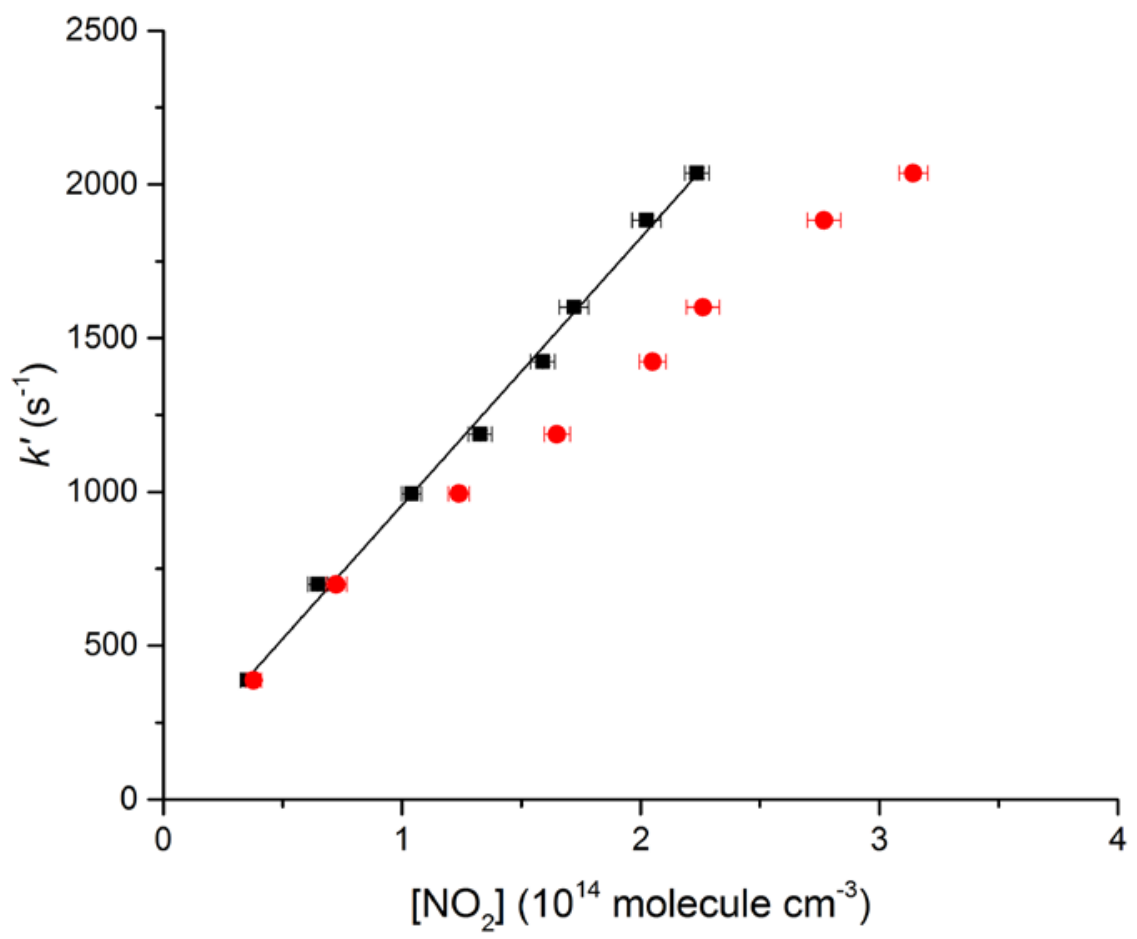

Figure S1. Red circles: Bimolecular plot of the $\mathrm{OH}$ reaction with $\mathrm{NO}_{2}$ measured at 78.8 Torr $\mathrm{N}_{2}$ and $217 \mathrm{~K}$. The black squares were obtained by accounting for loss of $\mathrm{NO}_{2}$ via $\mathrm{N}_{2} \mathrm{O}_{4}$ formation. 


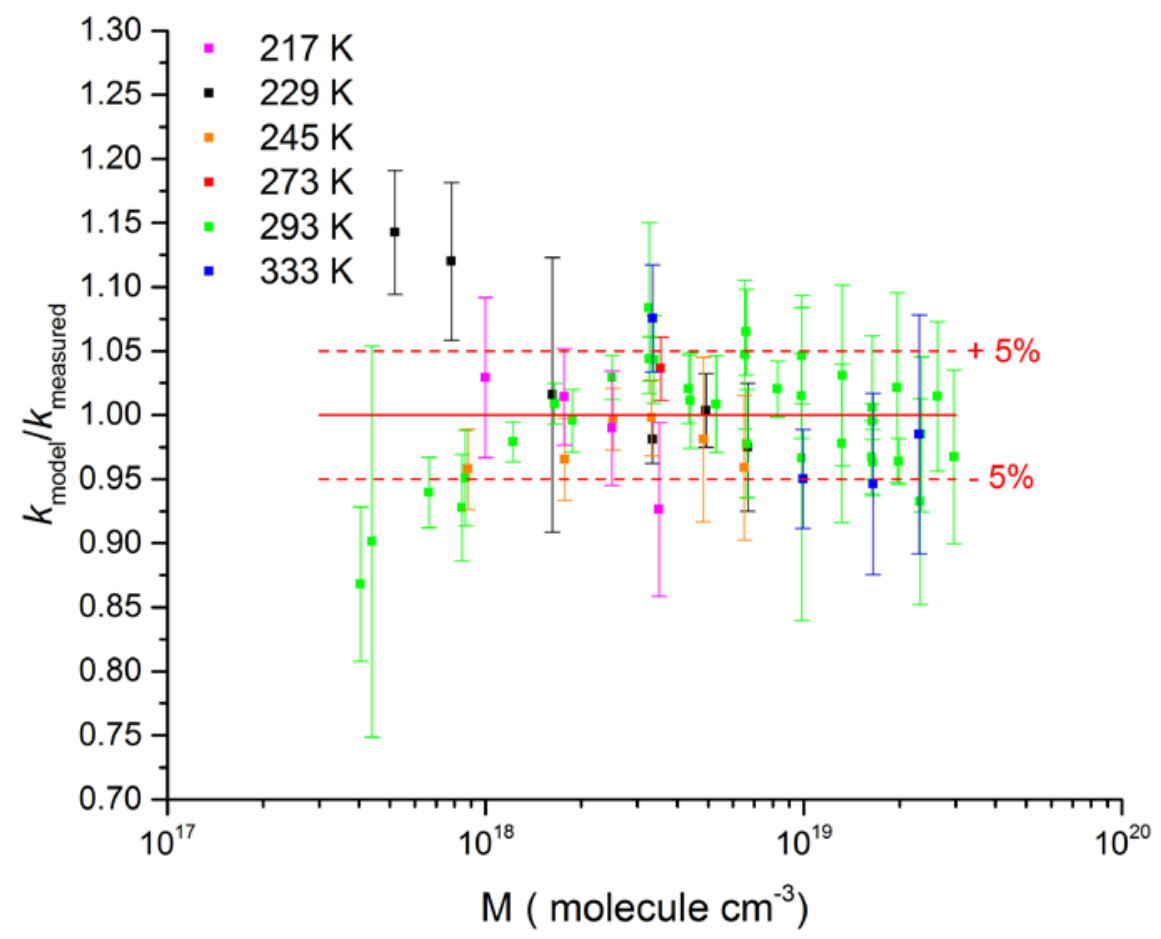

Figure S2. Ratio of the parametrised rate coefficient ( $\left.k_{\text {param }}\right)$ to measurements $\left(k_{\text {meas }}\right)$ as a function of the molecular density (M) for 6 different temperatures. 


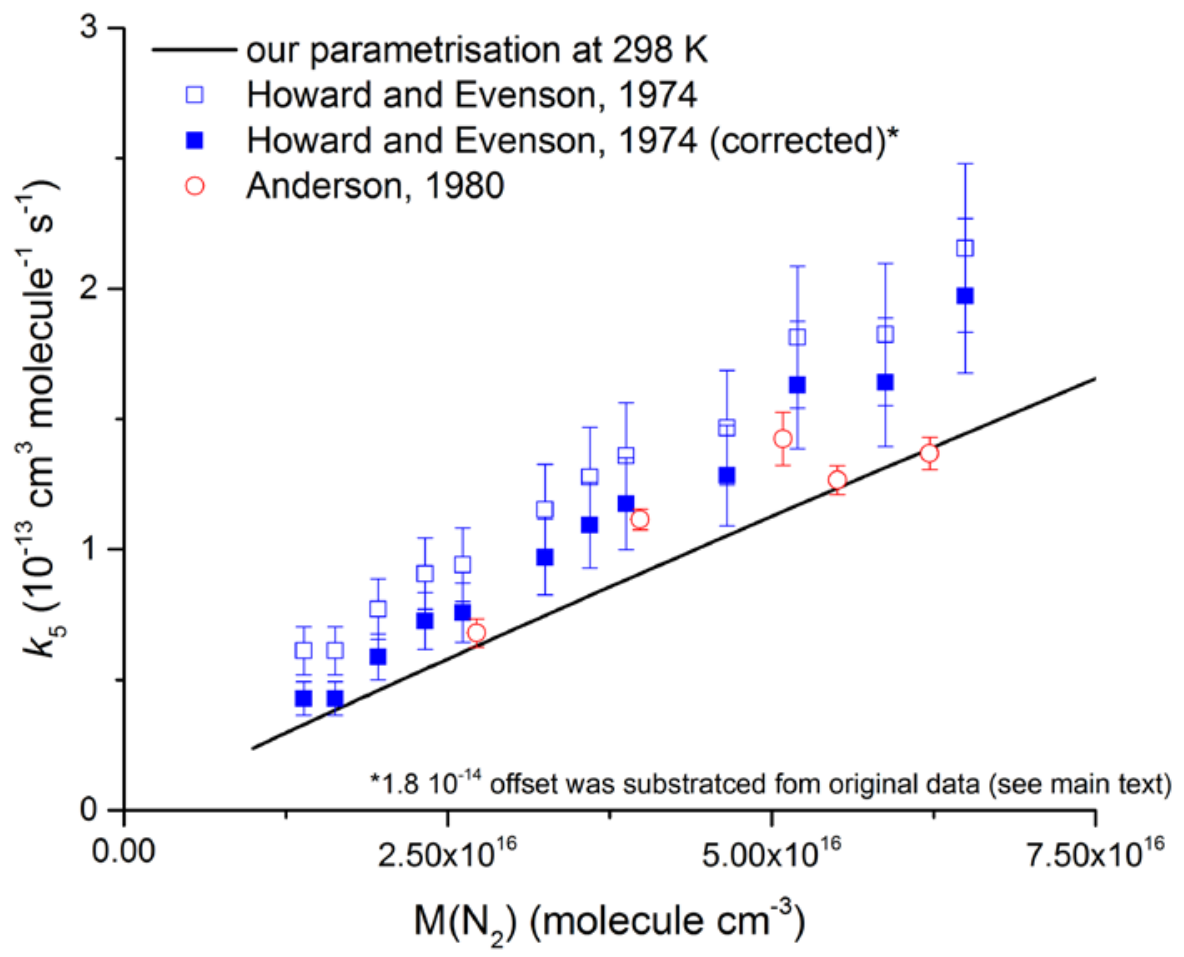

Figure S3. Comparison of the present parametrisation with low-pressure measurements by Howard and Evenson (1974) (open and closed blue squares) and Anderson (Anderson, 1980) (open red circles). 


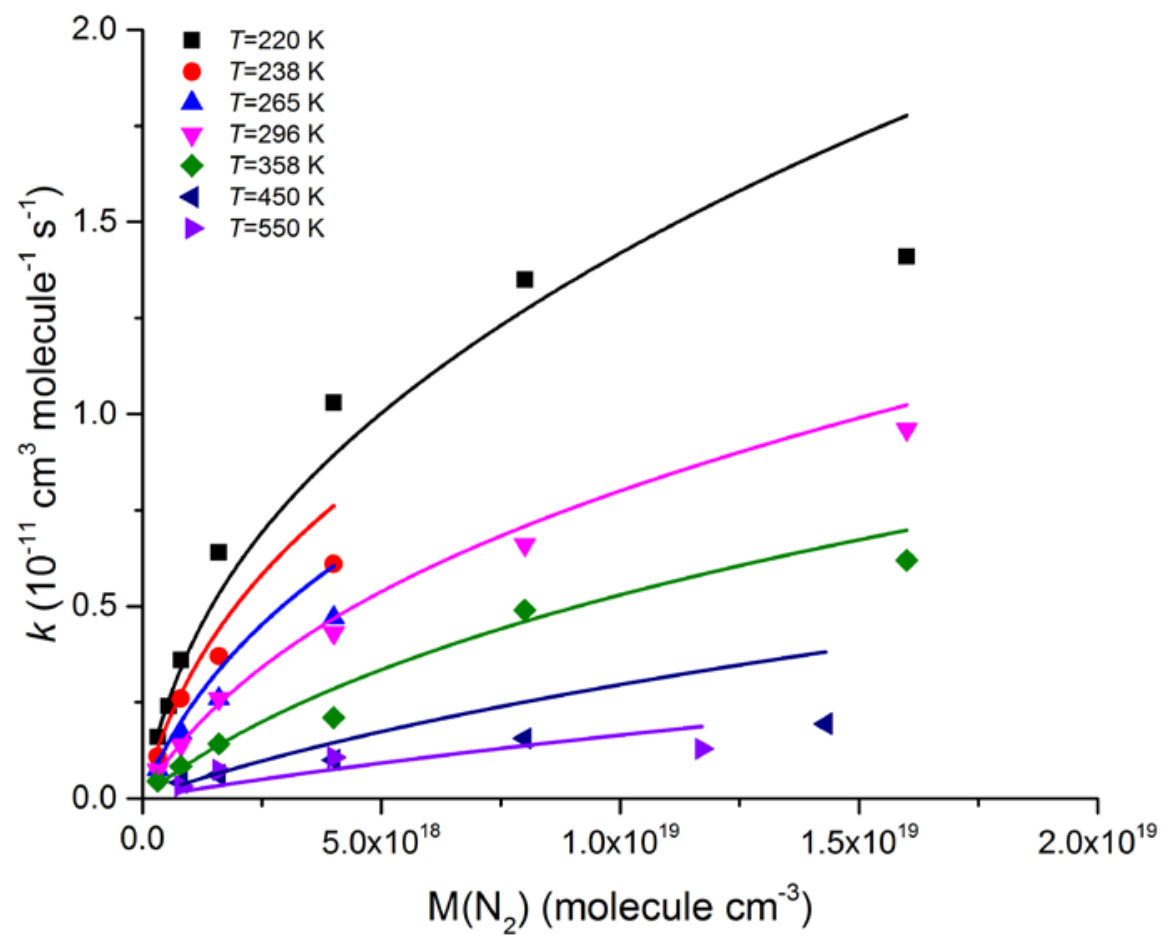

Figure S4. Comparison of the present parametrization with values of $k_{5}$ reported by Anastasi and Smith (1976), who report $36 \%$ overall uncertainty in $k_{5}(2 \sigma)$ 


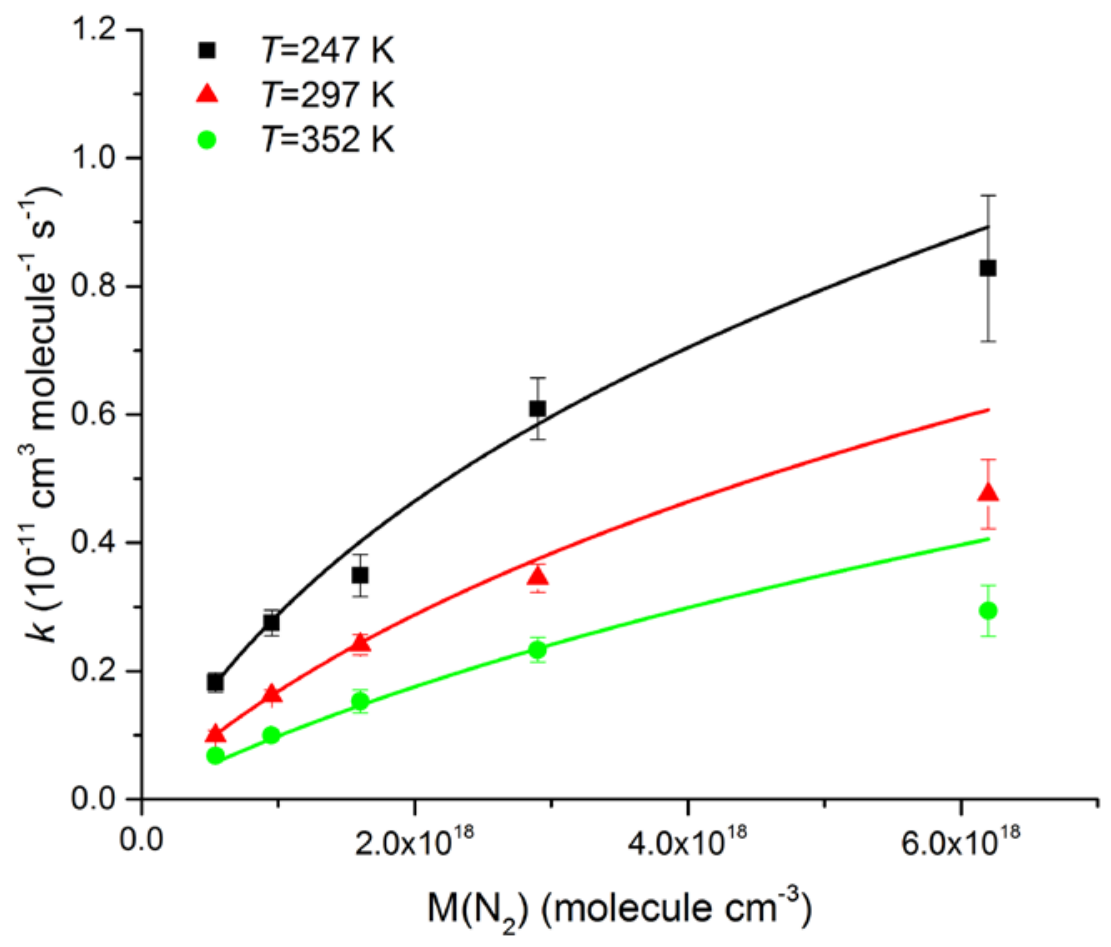

Figure S5. Comparison of the present parametrization with values of $k_{5}$ reported by Wine et al. (1979) where the error bars $(2 \sigma)$ represent total overall uncertainty. 


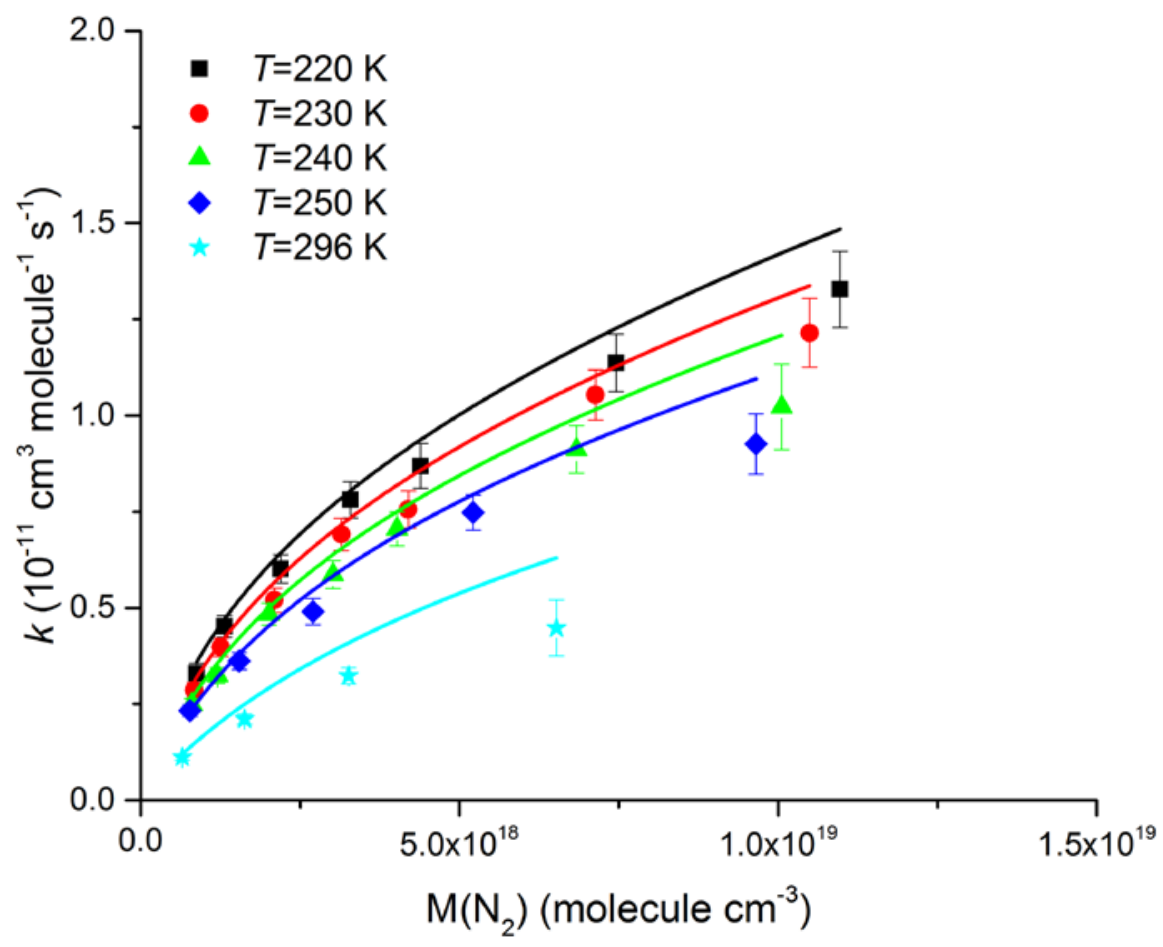

Figure S6. Comparison of the present parametrization with values of $k_{5}$ reported by Brown et al. (1999) where the error bars $(2 \sigma)$ represent total overall uncertainty. 


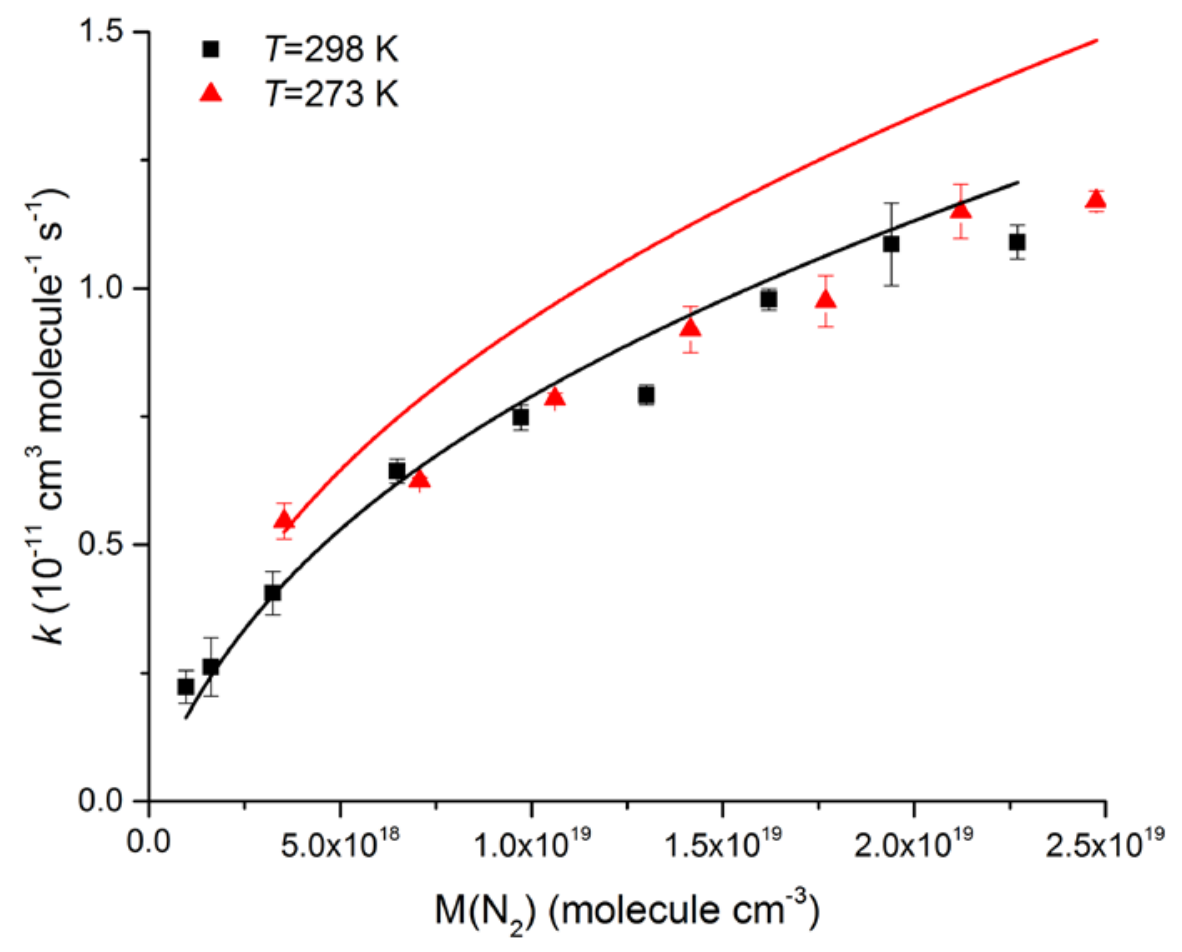

Figure S7. Comparison of the present parametrization with values of $k_{5}$ reported by D'Ottone et al. (2001) where the error bars $(2 \sigma)$ represent total overall uncertainty. 


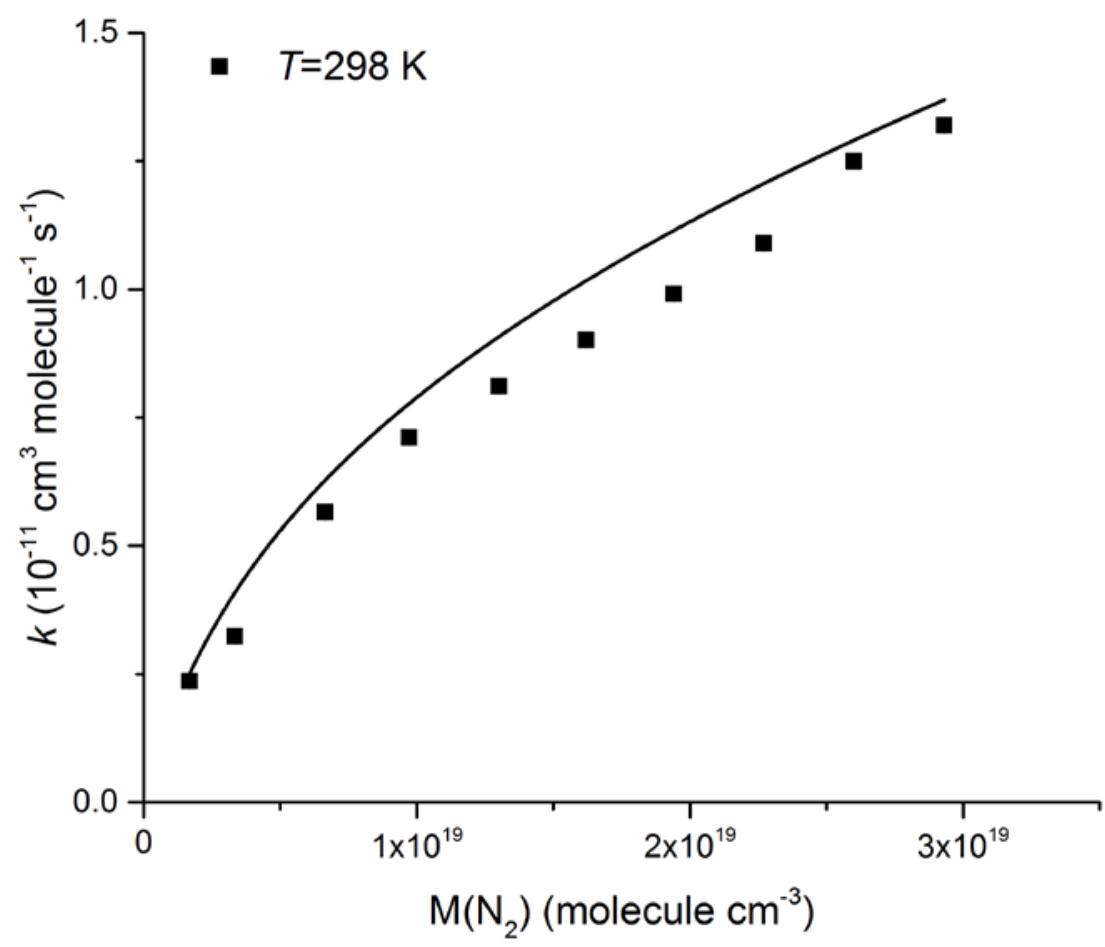

Figure S8. Comparison of the present parametrization with values of $k_{5}$ reported by Mollner et al. (2010). The reported $2 \sigma$ (statistical) uncertainty is $<2 \%$ is within the symbol size. 


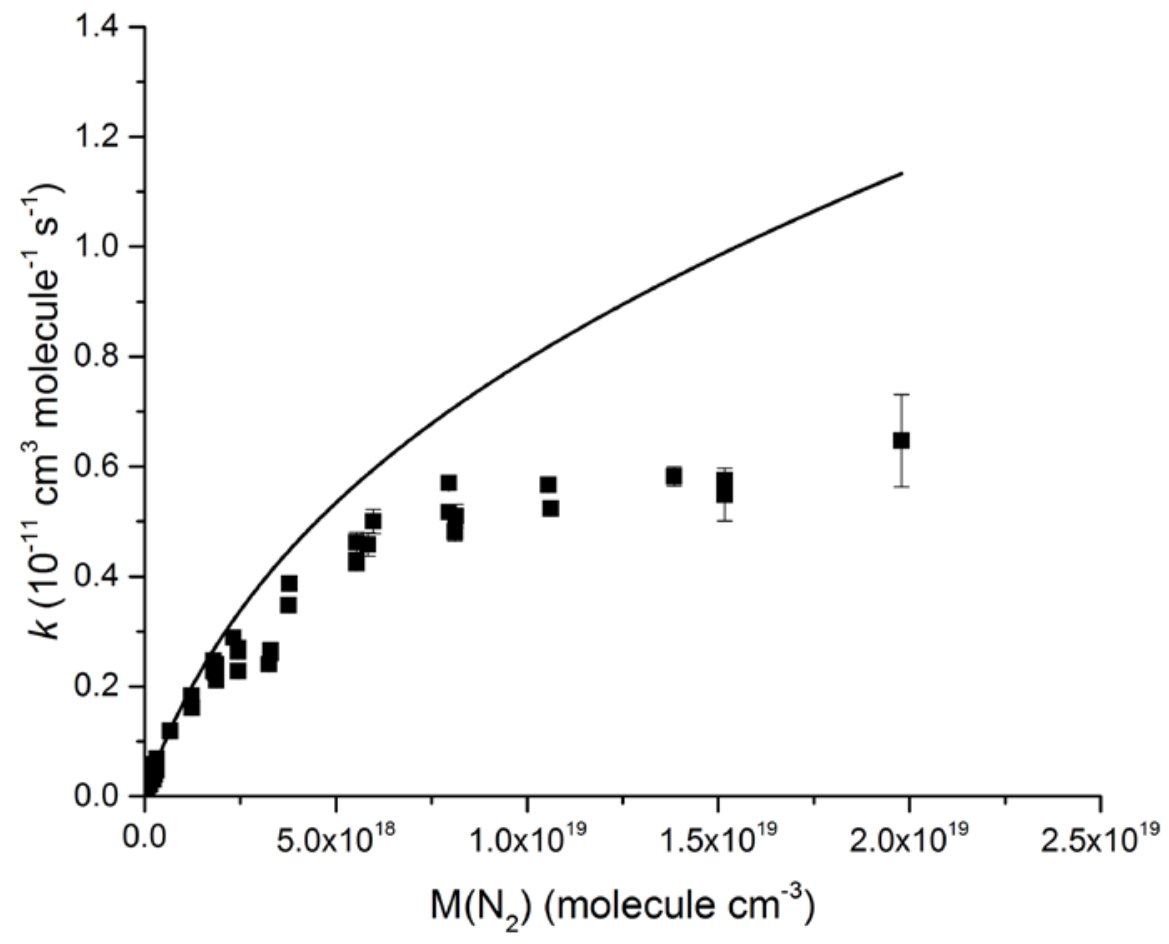

Figure S9. Comparison of the present parametrization with values of $k_{5}$ reported by Donahue et al. (1997) where the error bars $(2 \sigma)$ represent total overall uncertainty. 


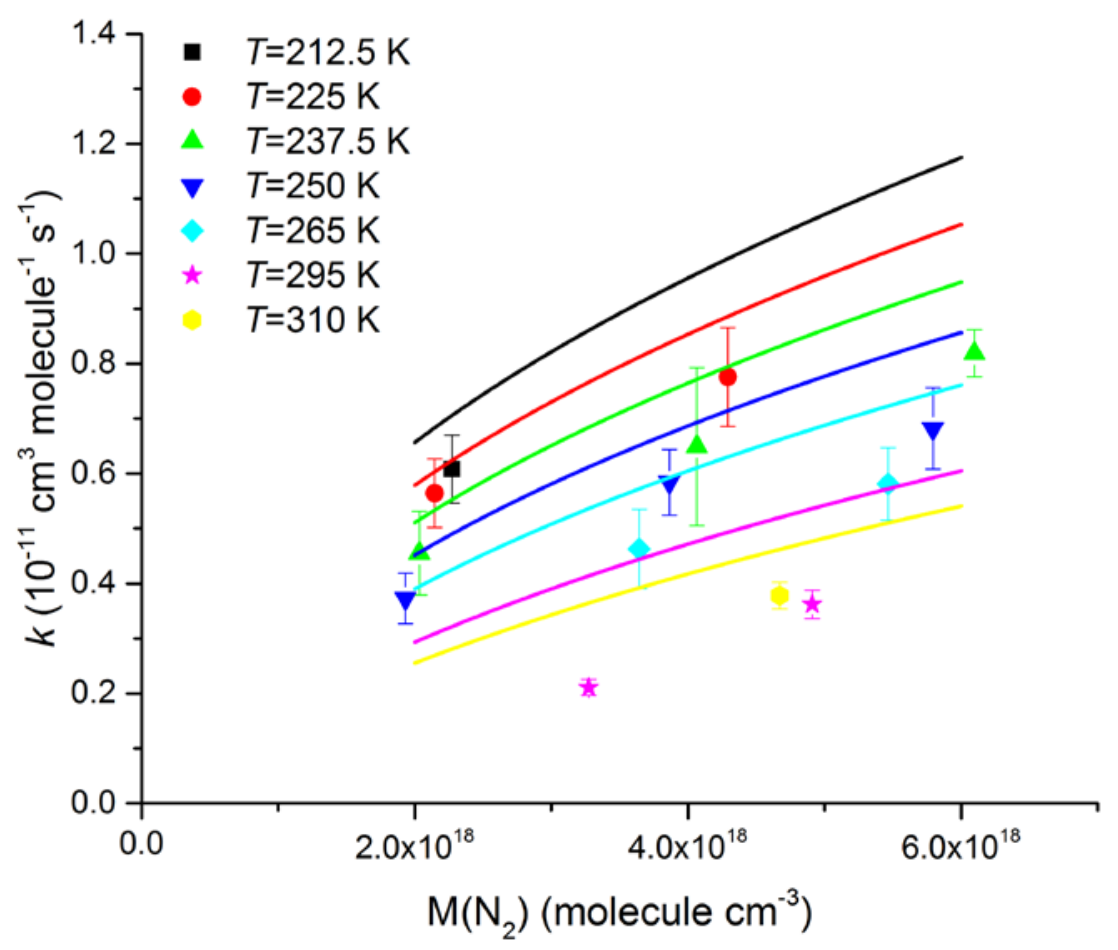

Figure S10. Comparison of the present parametrization with values of $k_{5}$ reported by Dransfield et al. (1999). 


\section{References}

5

Anastasi, C. and Smith, I. W. M.: Rate measurements of reactions of $\mathrm{OH}$ by resonance absorption. Part 5.-Rate constants for OH + NO 2 $(+\mathrm{M})$-> $\mathrm{HNO}_{3}(+\mathrm{M})$ over a wide range of temperature and pressure, Journal of the Chemical Society, Faraday Transactions 2: Molecular and Chemical Physics, 72, 1459-1468, 1976.

Anderson, L. G.: Absolute rate constants for the reaction of $\mathrm{OH}$ with $\mathrm{NO}_{2}$ in $\mathrm{N}_{2}$ and He from 225 to 389 K, J. Phys. Chem., 84, 2152-2155, 101980.

Brown, S. S., Talukdar, R. K., and Ravishankara, A. R.: Rate constants for the reaction OH+NO2+M -> HNO3+M under atmospheric conditions, Chem. Phys. Lett., 299, 277-284, 1999.

D'Ottone, L., Campuzano-Jost, P., Bauer, D., and Hynes, A. J.: A pulsed laser photolysis-pulsed laser induced fluorescence study of the kinetics of the gas-phase reaction of $\mathrm{OH}$ with NO2, J. Phys. Chem. A, 105, 10538-10543, 2001.

15 Donahue, N. M., Dubey, M. K., Mohrschladt, R., Demerjian, K. L., and Anderson, J. G.: High-pressure flow study of the reactions OH+NOx>HONOx: Errors in the falloff region, J. Geophys. Res. -Atmos., 102, 6159-6168, 1997.

Dransfield, T. J., Perkins, K. K., Donahue, N. M., Anderson, J. G., Sprengnether, M. M., and Demerjian, K. L.: Temperature and pressure dependent kinetics of the gas-phase reaction of the hydroxyl radical with nitrogen dioxide, Geophys. Res. Lett., 26, 687-690, 1999.

Howard, C. J. and Evenson, K. M.: Laser magnetic-resonance study of gas-phase reactions of OH with CO, NO, and NO 2 , J. Chem. Phys., 61, 1943-1952, 1974.

Mollner, A. K., Valluvadasan, S., Feng, L., Sprague, M. K., Okumura, M., Milligan, D. B., Bloss, W. J., Sander, S. P., Martien, P. T., Harley, R. A., McCoy, A. B., and Carter, W. P. L.: Rate of gas phase association of hydroxyl radical and nitrogen dioxide, Science, 330, 646-649, 2010.

Wine, P. H., Kreutter, N. M., and Ravishankara, A. R.: Flash photolysis-resonance fluorescence kinetics study of the reaction $\mathrm{OH}_{+}+\mathrm{NO}_{2}$ $25+\mathrm{M}->\mathrm{HNO}_{3}+\mathrm{M}$, J. Phys. Chem., 83, 3191-3195, 1979. 